\title{
Letters
}

Website: bmj.com

Email: letters@bmj.com

\section{Childhood obesity}

\section{Breast feeding is important}

EDITOR-Frühbeck does not consider the role of infant feeding in the aetiology of childhood overweight and obesity. ${ }^{1}$ Dewey et al found that formula fed infants were heavier than those who received no milk other than breast milk in the first 12 months, although they were of similar length and head circumference. ${ }^{2}$ The study also found that the energy intake of breastfed infants was lower than that of formula fed infants, even after the introduction of solids, and suggested that relatively low energy intakes are a function of self regulation in breastfed infants.

Von Kries et al found in children aged 5 and 6 years a substantial, dose dependent, protective effect of breast feeding on obesity and overweight: three to five months of exclusive breast feeding was associated with a $35 \%$ reduction in obesity at the age of 5 to 6 years. They discuss the evidence for a programming effect of breast feeding in preventing obesity and overweight in later life. ${ }^{3}$ Breast feeding mothers lose weight after pregnancy more effectively than those who feed artificially, an advantage seen over at least the first 12 months of breast feeding. ${ }^{4}$ It seems that promoting and supporting breast feeding should be part of the initiative to tackle the "epidemic of obesity."

\footnotetext{
Carol Campbell clinical medical officer
}

Community Paediatric Department, Foyle Health and Social Services Trust, Londonderry BT47 1TG ccampbell@btinternet.com

1 Frühbeck G. Childhood obesity: time for action, not complacency. BMJ 2000;320:328-9. (5 February.)

Dewey KG, Heinig MJ, Nommsen LA, Peerson JM, Lonnerdal B. Growth of breast-fed and formula-fed infants from 0 to 18 months: the DARLING Study. Pediat rics 1992;89:1035-41.

3 Von Kries R, Koletzko B, Sauerveld T, von Mutius E, Barnert D, Grunert V, et al. Breast feeding and obesity: cross sectional study. BMJ 1999;319:147-50.

4 Dewey KG, Heinig MJ, Nommsen LA. Maternal weight loss patterns during prolonged lactation. Am J Clin Nutr 1993;58:162-6.

5 Mayor S. European plan to put obesity on governments' health agenda. $B M J$ 1999;318:1574

\section{Aim should be weight maintenance, not loss}

EDITOR-Frühbeck's call for action over childhood obesity was heartening. ${ }^{1}$ However, we have concerns about the focus of the editorial.

Firstly, we believe that weight maintenance rather than weight loss should be the goal of treatment of obesity in childhood while height growth continues. Weight loss is difficult to achieve, and drop-out rates are up to $90 \%$ in large series. ${ }^{2}$ Additionally, ill-advised intake restriction may compromise nutrition and growth during vulnerable periods. Weight maintenance during the growing years is more easily achieved than weight $\operatorname{loss}^{3}$ and results in a gradual loss of overweight as height growth occurs. Weight maintenance is achieved by developing a stable energy balance and may therefore be more likely to result in long term maintenance of a healthy weight.

Secondly, the author failed to recognise the need for different approaches to the treatment of obesity in early childhood, late childhood, and adolescence, particularly in regard to the role of the family. A family centred approach is essential in early childhood as parents rather than children are responsible for the child's intake and energy expenditure. In later childhood and adolescence, individual work is needed with the young person but within the context of family involvement. ${ }^{45}$

We agree that there is no room for complacency over childhood obesity. However, the results of existing treatment programmes are generally disappointing, given the expense of multidisciplinary involvement. Much further work is needed to develop effective treatment programmes that can be undertaken by community health professionals. Early intervention by programmes that emphasise weight maintenance while height growth continues in childhood and early adolescence may offer the best and most cost effective way of preventing the morbidity associated with adult obesity.

Russell Viner honorary senior lecturer in adolescent medicine

University College London Medical School, Middlesex Hospital, London W1N 8AA R.Viner@ich.ucl.ac.uk

Rachel Bryant-Waugh consultant clinical psychologist

Great Ormond Street Hospital for Children, London WC1N 3JH

Dasha Nicholls lecturer in behavioural sciences Institute of Child Health, Great Ormond Street Hospital for Children

Deborah Christie consultant clinical psychologist Middlesex Adolescent Unit, Middlesex Hospital, London W1N 8AA

1 Frühbeck G. Childhood obesity: time for action, not complacency. BMJ 2000;320:328-9. (5 February.)

2 Pinelli L, Elerdini N, Faith MS, Agnello D, Ambruzzi A, De Simone M, et al. Childhood obesity: results of a multicenter study of obesity treatment in Italy. J Pediatr Endocrinol Metab 1999;12:795-9.
3 Braet C, Van Winkel M, Van Leeuwen K. Follow-up results of different treatment programs for obese children. Acta Paediatr 1997;86:397-402.

4 Epstein LH. Family-based behavioural intervention for obese children. Int J Obes Relat Metab Disord 1996;20(suppl 1):S14-21.

5 Epstein LH, Valoski A, Wing RR, McCurley J. Ten-year outcomes of behavioral family-based treatment for childhood obesity. Health Psychol 1994;13:373-83.

\section{Opportunity for physical activity has} been lost

EDITOR-I was surprised that Frühbeck failed to mention the societal factors that have had such a pivotal role in the development of childhood obesity. ${ }^{1}$ The energy intake of preschool children has actually declined over the past 10 years, ${ }^{2}$ but this has been outstripped by an increase in inactivity. ${ }^{3}$ Obesity has been created by structural changes that have reduced our nation's ability to make healthy choices. It is a political problem that demands political changes rather than behavioural or pharmacological interventions. We must create a less obesogenic environment for our children. ${ }^{4}$

As a child in the fifties I played in the street With hope in my heart and a ball at my feet My friends and I were out every day Life was just perfect child's play

We cycled our bikes far and wide

Into the welcoming countryside

Climbing in trees, fishing in streams At night I had such sweet, sweet dreams

\section{Advice to authors}

We prefer to receive all responses electronically, sent either directly to our website or to the editorial office as email or on a disk. Processing your letter will be delayed unless it arrives in an electronic form.

We are now posting all direct submissions to our website within 24 hours of receipt and our intention is to post all other electronic submissions there as well. All responses will be eligible for publication in the paper journal.

Responses should be under 400 words and relate to articles published in the preceding month. They should include $\leqslant 5$ references, in the Vancouver style, including one to the BMJ article to which they relate. We welcome illustrations.

Please supply each author's current appointment and full address, and a phone or fax number or email address for the corresponding author. We ask authors to declare any competing interest. Please send a stamped addressed envelope if you would like to know whether your letter has been accepted or rejected.

Letters will be edited and may be shortened.

bmj.com

letters@bmj.com 
Now in the Zeros my kids are denied Denied the childhood on which I thrived

Streets filled with cars, cars everywhere

Childhood destroyed, does anyone care?

In the streets where once I stayed

The cars are speeding

In the streets where once I played

Childhood now lies bleeding.

I am tired of reading articles bemoaning how our children spend all their time playing computer games and watching television. The sad reality is that most streets are now linear car parks with a central race track. It is too dangerous for children to play safely in their own streets. The Children's Play Council, Transport 2000, and Transform Scotland have been promoting a Dutch concept called home zones. ${ }^{5}$ These are streets that, with local community involvement, have been transformed into areas where children can play safely. Trees, picnic benches, and play equipment are placed in the street, and this physically prevents traffic from moving at more than $10 \mathrm{mph}$. Cars are guests, with pedestrians and cyclists having precedence. There are nine pilot schemes currently being monitored in England, and a few may soon begin in Scotland. Unfortunately, the funding is expected to come from already overstretched local authority transport budgets. Few home zones may ever be created. The relation between safe play and child health should be recognised centrally and ring fenced finance be provided to make all our neighbourhood roads into home zones.

Colin Guthrie general practitioner

Glasgow G14 9DW

grey triker@hotmail.com

1 Frühbeck G. Childhood obesity: time for action, not complacency. BMJ 1999;320:328-9. (5 February.)

2 Gregory JR, Collins DL, Davies PSW, Hughes JM, Clarke PC. National diet and nutrition survey: children aged 1.5-4.5 years. London: HMSO, 1993.

3 Pullinger J. Social trends. London: Stationery Office, 1998.

4 Egger G, Swinburn B. An "ecological" approach to the

Egger G, Swinburn B. An "ecological"
obesity pandemic. BMJ 1997;315:477-80.

5 Children's Play Council. www.cpc.ncb.org.u/cpc.htm

\section{Healthy schools approach is needed}

EDITOR-Frühbeck's editorial calls for action on childhood obesity. ${ }^{1}$ In Liverpool, guidelines for schools on eating disorders and body image have recently been launched. ${ }^{2}$ The guidelines are part of Liverpool's healthy schools award initiative. ${ }^{3}$ This is supported by the health authority and the city council and provides a coordinated approach to promoting health among school children. It forges links between education, health, parents, and the wider community to equip children and young people with the personal resources to empower them to pursue healthy lifestyles.

Frühbeck refers to the difficulty of maintaining, in the long term, classroom lessons on nutrition and physical health because of competition for school time. ${ }^{1}$ The approach taken in the healthy schools award is for food and nutrition (and eight other areas) to be included across the curriculum and in the general ethos of the school not as an "add-on." In relation to food and nutrition one of the indicators of success is "to develop a cross-curricular approach to teaching about food and nutrition which enables pupils and staff to make positive connections between a balanced diet, safe hygiene practices, and health."

One hundred and fifty eight Liverpool schools are taking part in the initiative, and since 1997, 40 have achieved the award. The recent guidelines provide information about eating disorders and how schools can establish an environment which encourages a positive body image to counter some of the societal pressures that may contribute to eating problems. ${ }^{2}$ Schools are encouraged to promote exercise and eating a healthy balanced diet as the most effective way to lose weight and maintain weight loss.

The healthy schools approach is being promoted nationally by the government in recognition that the school is a key setting in which to improve both health and education. ${ }^{4}$ Liverpool healthy schools programme is currently undergoing national accreditation following the launch of the national healthy schools scheme last year. The scheme provides national accreditation for education and health partnerships, and aims to ensure that evidence is gathered to demonstrate effectiveness. The standards that local healthy schools programmes must achieve for accreditation include taking a whole school approach to healthy eating and physical activity. ${ }^{4}$

The healthy schools approach is therefore an important means of acting to prevent and reduce childhood obesity and in time should provide evidence about the effectiveness of interventions.

Joyce Carter consultant in public health medicine Liverpool Health Authority, Liverpool L3 6AL joyce.carter@liverpool-ha.nwest.nhs.uk

Annette Lyons senior effectiveness officer, personal social and health education

City of Liverpool Education and Lifelong Learning Service, Liverpool L1 4NX 1 Frühbeck G. Childhood obesity: time for action, not com-
placency. BMJ 2000;320:328-9. (5 February.)
2 Butler K. Guidelines for schools on eating disorders and body
image. Liverpool:City of Liverpool Education and Lifelong
Learning Service, 2000 .
3 City of Liverpool Education and Lifelong Learning
Service. Liverpool healthy schools award manual. Liverpool:
CLELLS, 2000.
4 Healthy Schools. National healthy school standard-guidance.
Nottingham: Department for Education and Employment,
1999 .

\section{Interventions should be critically} evaluated

EDITOR-Frühbeck states that "English and Scottish children showed a roughly twofold increase in weight for height in all age groups and both sexes."' The study she cited, however, showed that Scottish, not English, children increased their weight. Based on a similar statement on the prevalence of overweight another editorial proposed: "to alter this trend, strategies and programs for weight maintenance as well as weight reduction must become a higher public health priority."' Many other articles use similar logic: the prevalence of obesity and obesity related disease emphasises the need for concerted efforts to prevent and treat obesity.
What is disturbing in this logic is that the strategic plan starts right from action rather than considering the evidence of effectiveness. Numerous trials of interventions have taken place, varying from exercise to drugs and surgery to interventions in schools. But these are "necessity driven" actions rather then evidence driven. Before children are denied access to television, games, and chocolates, let us look at the evidence. Although some interventions promise limited effectiveness in weight reduction, not one trial has shown prevention of weight gain in the population. Not one trial has shown gains in clinically important end points (mortality and morbidity) after weight reduction or obesity prevention interventions. US guidelines on obesity in adults, prepared with the participation of the Cochrane Collaboration, did not cite any study supporting the efficiency of interventions.

Perhaps absence of evidence is the main reason why "less than half of obese adults report being advised to lose weight by health care professionals." counselling about exercise is low. ${ }^{4}$ Perhaps this is because physicians do not want to act without evidence. I believe that physicians must not be pressed to advise patients to buy weight reducing devices, etc, before they have the evidence that treating or preventing obesity is worth while.

We must rethink the history of obesity research. It is strange that despite criticism of the methodology of the Metropolitan Life Insurance Company study, which showed reduced mortality in obese people who had reduced their body mass, no other study has addressed this important question in over 50 years.

Vasiliy Vlassov professor

Saratov Medical University, Saratov, 410601 Russia vvvla@sgu.ru

1 Frühbeck G. Childhood obesity: time for action, not complacency. BMJ 2000;320:328-9. (5 February.)

2 Mokdad AH, Serdula MK, Dietz WH, Bowman BA, Mark JS, Koplan JP. The spread of the obesity epidemic in the United States, 1991-1998. JAMA 1999;282:1519-22.

3 Galuska DA, Will JC, Serdula MK. Are health care professionals advising obese patients to lose weight? JAMA 1999;282:1576-8.

4 Wee CC, McCarthy EP, Davis RB, Phillips RS. Physician counseling about exercise. JAMA 1999;282:1583-8.

\section{Author's reply}

EDITOR-Editorials are constrained by lack of space and are not intended to be a wide ranging review but to highlight, as succinctly as possible, the basics of knowledge to date. Obesity has reached epidemic proportions. Thus, the epidemiological triad of host, agent, and environment can be used to consider causal factors. Features of the host affect obesity in ways that are not well understood. Some people seem more susceptible than others to weight gain. Campbell rightly points out the important role of breast feeding in preventing obesity in later life. Undoubtedly, factors that signal and regulate postnatal growth contribute to development of diseases in adulthood. In utero programming as well as nutritional programming during fetal life may result in permanent modifications of the neuro- 
endocrine responses that are carried forward into adulthood.

In this epidemiological triad the agent is energy imbalance, where energy intake exceeds energy expenditure. The main modifiable factors affecting energy balance are dietary energy intake and energy expended through physical activity. I agree with Viner and colleagues that different approaches are needed to treat obesity in early childhood, late childhood, and adolescence. However, I do not share their view that weight maintenance rather than weight loss should be the goal. Merely concentrating on weight maintenance in overweight or obese children, hoping that they will grow out of the condition, has been shown to be ineffective and will not stem the escalating numbers of children entering medically defined categories of ill health. ${ }^{1}$

The third entity is environment. This encompasses not just the physical environment, such as the layout of the cities, but economic and social organisation and cultural values. I agree with Guthrie that a less obesogenic environment for children has to be created. In this sense, the public health would benefit from going beyond a narrowly mechanistic focus on energy intake and physical activity and examining the economic, social, and cultural context more broadly. The best way to combat the problem is to help children avoid becoming overweight in the first place. The Liverpool healthy schools programme is welcome and represents the example to be followed. Clinical medicine and public health agencies have to act to prevent obesity with new partners, including food marketers and manufacturers, public and private healthcare purchasers, large employers, transportation agencies, urban planners, and real estate developers.

I admire Vlassov's diligence in scrutinising my references. To be precise, increases in all measurements (height, weight, and triceps skinfold thickness) except weight for height in English boys were found in the 1972,1982 , and 1990 surveys of the national study of health and growth. Data from the health survey for England 1996, a nationally representative sample of 2630 English children, showed that the frequency of overweight ranged from $22 \%$ at age 6 years to $31 \%$ at age 15 and that obesity ranged from $10 \%$ at 6 years to $17 \%$ at 15 years. ${ }^{1}$ This reflects a rapid increase in overweight and obesity compared with previous UK surveys.

Despite Vlassov's claim, recommendations on obesity are evidence based. Vlassov is apparently not familiar with the systematic assessment and management approach based on evidence available from scientific studies and clinical trials, with primary care having a central role. The evidence report of the National Institutes of Health and the consultation convened by the World Health Organization are two excellent examples. ${ }^{23}$ Vlassov is equally misguided about the absence of evidence regarding the benefits of treating or preventing obesity. Even modest reductions in weight of $5-10 \%$ of initial body weight are effective in decreasing associated comorbidity. ${ }^{4}$ Furthermore, a recently published prospective study of more than a million adults in the United States (457 785 men and 588369 women) supported the well established increase in the risk of death from all causes, cardiovascular disease, cancer, or other diseases throughout the range of moderate and severe overweight for both men and women in all age groups. ${ }^{5}$

Gema Frühbeck clinical scientist

Department of Endocrinology, Clinica Universitaria de Navarra, University of Navarra, 31008

Pamplona, Spain

gfruhbeck@unav.es

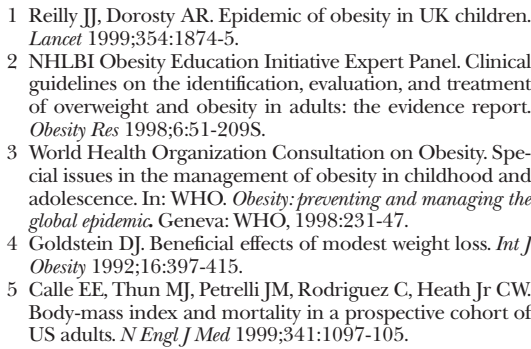

US adults. N Engl J Med 1999;341:1097-105.

\section{Visual field defect associated with vigabatrin}

\section{Many more patients may be affected than} were found in study

EDITOR-We note that Wilton at al report an increase in the number of confirmed cases of visual field defects attributed to vigabatrin in their observational cohort study. ${ }^{1}$ However, both of their studies were based on questionnaires. Since many of the visual field defects observed in epileptic patients treated with vigabatrin are asymptomatic and the field loss may begin in the periphery, as in glaucoma, ${ }^{2}$ we suspect that many more patients have visual field defects than is implied by these data.

We recently presented data on 14 epileptic patients treated with vigabatrin (cases) to the International Society for Clinical Electrophysiology of Vision. We compared their visual fields and electrophysiological results with those of 10 epileptic patients taking other drugs (controls). Most of the cases had some degree of field loss, mostly mild constriction, but in three of them changes were grossly abnormal. None of the controls had field loss.

Ten of the 14 patients taking vigabatrin had a reduced Arden ratio in at least one eye. Nine of the 10 controls had a normal ratio, and the mean ratio was significantly different in the two groups. Various aspects of the electroretinogram were abnormal in at least half of the cases in at least one eye. Mean photopic b-wave amplitudes were significantly reduced in cases compared with controls, as were mean oscillatory potential amplitudes and latencies. Only one control had slightly reduced photopic b-wave amplitude in one eye.

Only two patients taking vigabatrin had symptoms. We continue to collect data on epileptic patients treated with other anti- convulsants as well as vigabatrin, but, even with these numbers, results have been significantly different between the groups. We have found that changes persist long after stopping treatment with the drug. Other groups agree with us that long term treatment with vigabatrin may predispose to irreversible visual changes. ${ }^{3}$ The manufacturer suggests that visual field loss may occur in a third of subjects, but we suspect it is even more common. Patients taking vigabatrin must have their visual field monitored; in cases in which this is difficult, electrophysiological results may help. Prescribers should note that special considerations apply to children (see letter from the Vigabatrin Study Group, next page).

I F Comaish specialist registrar in ophthalmology Comaish@aol.com

C Gorman specialist registrar in ophthalmology N R Galloway consultant ophthalmologist University Hospital, Queen's Medical Centre, Nottingham NG7 2UH

Competing interests: None declared.

1 Wilton LV, Stephens MOB, Mann RD. Visual field defect associated with vigabatrin: observational cohort study. $B M$ 1999;319:1165-6. (30 October.)

2 Kälviäinen R, Nousiainen I, Mäntyjärvi M, Nikoskelainen E, Partanen J, Partanen K, et al. Vigabatrin, a gabaergic antiepileptic drug, causes concentric visual field defects. Neurology 1999;53:922-6.

3 Miller NR, Johnson MA, Paul SR, Girkin CA, Perry JD, Endres M, et al. Visual dysfunction in patients receiving vigabatrin: clinical and electrophysiologic findings. Neurology 1999;53:2082-7

\section{Method of estimating prevalence was inappropriate}

EDITOR-I was surprised by the low rate of visual field defects associated with vigabatrin found by Wilton et al in their cohort of 7228 patients $(0.8 \%),{ }^{1}$ especially when the manufacturer estimates the prevalence to be between $10 \%$ and $30 \%{ }^{2}$

On closer examination, I note that Wilton et al used a questionnaire sent to the general practitioners of patients taking vigabatrin as their main source of data to identify patients with visual field problems. This method is completely inappropriate because, as with glaucoma, the visual field defects associated with vigabatrin are usually totally asymptomatic until the very late stages when the field defects start to encroach on fixation. Thus most patients with visual field defects would be missed if they were to be identified by the presence of symptoms. This is why recent guidance from the manufacturer, Hoechst Marion Roussel, suggests that patients taking vigabatrin should have their visual fields assessed every six months whenever possible. ${ }^{2}$

Moreover, in a case-control study on vigabatrin and associated field defects that I and others have recently submitted for publication we found a significant relation between total dose of vigabatrin and associated visual field defects. Visual field defects seemed to be especially noticeable after an accumulated dose of $2.5 \mathrm{~kg}$.

Kaykhosrov Manuchehri specialist registrar in ophthalmology

Birmingham and Midland Eye Centre, City

Hospital, Birmingham B18 7QU

harrj@dircon.co.uk

Competing interests: None declared. 
1 Wilton LV, Stephens MOB, Mann RD. Visual field defect associated with vigabatrin: observational cohort study. $B M J$ 1999;319:1165-6. (30 October.)

2 Hoechst Marion Roussel. Important information on pharmacovigilance, 27 August 1999. (After review by Committee for Proprietary Medicinal Products.)

\section{Means of selecting patients was misleading}

EDITOR-Wilton et al reported an incidence of risk of visual field defects probably or possibly related to vigabatrin of 7.0 per 1000 patients. ${ }^{1}$ The study entailed sending a questionnaire to the treating general practitioner and selecting patients referred for visual problems to ophthalmologists.

According to my and others' experience, ${ }^{23}$ this means of selection might be misleading because most patients with visual field defects associated with vigabatrin are symptom-free. Furthermore, no consensus has yet been reached on the best way of detecting visual field defects early. The manufacturer suggests static perimetry as a standard method, ${ }^{4}$ but some uncertainty still exists about how to examine the periphery of the visual field and evaluate the results.

I have examined several patients receiving vigabatrin in whom standard examination tests in the central $30^{\circ}$ of the visual field showed normal results, although they had defects in the periphery. Furthermore, the deleterious effect of vigabatrin might be overlooked in patients with visual field defects from other causes.

I recently examined the visual field of a 37 year old woman with a complete left sided hemianopsia due to a cerebral haemorrhage at birth. She had taken vigabatrin since 1992 and had been referred for visual field testing, although none of her symptoms had worsened. The test showed a complete left homonymous hemianopsia. However, in addition, a nasal defect was found in the periphery of the visual field in her left eye that might have been associated with vigabatrin treatment. On the right side, the possible loss could not be evaluated owing to overlap with the pre-existing defect in the nasal hemifield. This observation supports the recent recommendation from the manufacturer to consider other antiepilepsy drugs in patients having visual field defects before starting treatment. ${ }^{4}$

In my experience, visual field defects possibly related to vigabatrin treatment are encountered more frequently than the results from the study of Wilton et al imply. In the light of the recent study showing visual field defects in as many as 40\% of patients taking vigabatrin, ${ }^{3}$ awareness about this possible side effect needs to be increased among doctors and patients. Furthermore, clinical guidance on the examination of visual fields and evaluation of the results is urgently needed.

Anna Midelfart professor

Department of Ophthalmology, Faculty of Medicine, Norwegian University of Science and Technology, 7005 Trondheim, Norway anna.midelfart@medisin.ntnu.no

Competing interests: None declared.
1 Wilton LV, Stephens MOB, Mann RD. Visual field defect associated with vigabatrin: observational cohort study. $B M$ 1999;319:1165-6. (30 October.)

2 Krauss G L, Johnson M A, Miller N R. Vigabatrinassociated retinal cone system dysfunction. Electroretinogram and ophthalmologic findings. Neurology 1998; 50: 614-18.

3 Kälviäinen R, Nousiainen I, Mäntyjärvi M, Nikoskelainen E, Partanen J, Partanen K, et al. Vigabatrin, a gabaergic antiepileptic drug, causes concentric visual field defects. Neurology 1999:53:922-6.

4 Hoechst Marion Roussel. Viktig informasjon vedrørende terapeutisk bredde. Synsfeltinnskrenkning hos pasiente behandlet med vigabatrin. (Letter to Norwegis pasiente behandle med igabatrin. (Letter to Norwegian Phys October 1999.

\section{Author's reply}

EdiTor-We thank Comaish et al, Manucheri, and Midelfart for the information they provide on the subject of visual field defects in patients treated with vigabatrin. Our initial study was conducted between 1991 and 1994 to monitor the safety of vigabatrin soon after it was marketed by using an observational cohort technique, prescription event monitoring. With this method previously unrecognised adverse events may be identified in large cohorts of patients-10033 in our study, among the first patients in England to be prescribed vigabatrin. The signal that visual field defects may be a long latency adverse reaction associated with vigabatrin was identified in this study, confirming the findings of Eke et al, who published the first report of this signal. ${ }^{1}$ The manufacturer was notified of our findings in 1995.

Our method was not designed to address the question of the incidence of asymptomatic visual field defects, and we agree with both Comaish et al and Midelfart that visual field defects in patients taking vigabatrin may be more common than the number of such cases identified in our cohort. We do not agree with Midelfart that our selection might be misleading: we did not select the patients as ours was an observational study. Neither do we see eye to eye with Manucheri that our method was completely inappropriate; he is addressing a different question from that which captured our attention. In fact, prescription event monitoring not only was successful in strengthening this safety signal but provided some indication of the incidence of detected visual field defects in a large cohort of patients being treated with vigabatrin in the community at this time (1998).

During 1997 and 1998 letters were published in the $B M J$ on visual field defects and vigabatrin, some of which recommended regular visual field testing. ${ }^{2-4}$ Only a small proportion $(<2 \%)$ of the 4741 patients in our follow up study were referred for visual field testing. Of these 89 cases, $36(40 \%)$ had objective evidence of a visual field defect and $30(34 \%)$ were considered to be probably or possibly associated with vigabatrin use. Our study was conducted during 1998, before the latest guidance from Hoescht Marion Roussel was available.

To understand fully clinically important adverse drug reactions, a range of scientific approaches is usually necessary, including community based observational studies. Evaluation of the data requires understand- ing of the strengths and weaknesses of each method.

L V Wilton senior research fellow

Drug Safety Research Unit, Southampton SO31 1AA

Competing interests: None declared.

1 Eke T, Talbot JF, Lawden MC. Severe persistent visual field constriction associated with vigabatrin. BMJ 1997; 314:180-1.

2 Wong ICK, Mawer GE, Sander JWAS. Severe persistent visual field constriction associated with vigabatrin. BMJ 1997;314:1693-4.

3 Blackwell N, Hayllar J, Kelly G. Severe persistent visual field constriction associated with vigabatrin. BMJ 1997; 314:1694.

4 Rao GP, Ah Fat F, Kyle G, Leach JP, Chadwick DW, Batterbury M. Study is needed of visual field defects associated with any long term antiepileptic drug. BMJ 1998;317:206. 5 Hoescht Marion Rousell. Important information on pharmacovigilance, 27 August 1999. (After review by Committee for Proprietaryst 1999. (After reve

\section{Guideline for prescribing vigabatrin in children has been revised}

EDITOR-In 1998 a paediatric advisory group in the United Kingdom produced a guideline to help clinicians when prescribing vigabatrin in children. ${ }^{1}$ The visual field defect reported in association with the drug ${ }^{2}$ has now been confirmed in five children treated with it. The paediatric guideline has now been revised and replaced with the one below, which reflects the current opinion of the advisory group.

- The defect is specific-a bilateral and concentric constriction that, within a $30^{\circ}$ radius from fixation, consists of a nasal loss extending in an annulus over the horizontal midline, with a relative sparing of the temporal field. Its pathogenesis is thought to involve cone and amacrine cell dysfunction in the retina. The prevalence in adults is about $30 \%{ }^{3}$; that in children is not established. The relation between the duration of exposure to vigabatrin and the development of the field defect is not known. Neither recovery nor progression of the defect has been confirmed after withdrawal of the drug. Confrontation testing does not reliably identify the defect.

- Children with a cognitive age of $\geqslant 9$ should undergo visual field examination with a Goldmann perimeter (11e or 12e isopter and $14 \mathrm{e}$ or $\mathrm{V} 4 \mathrm{e}$ isopter) or a Humphrey field analyser (age related, three zone suprathreshold strategy and the 135 point field) before vigabatrin is prescribed and, ideally, every six months, particularly if they continue to take the drug.

- For children aged $<9$ a field specific visual evoked potential technique to assess peripheral vision is being evaluated in children with epilepsy ${ }^{4}$ but is not yet routinely available.

- Electroretinography performed according to international standards has shown abnormalities of cone function in adults and may be useful in children.

The continued prescription of vigabatrin remains one of risk versus benefitthe potential risk of the visual field defect developing against the potential benefit of 
seizure control. One specific risk is the implications of a field defect for driving in a patient with epilepsy who is seizure free.

- Children who have, or are at risk of developing, a visual defect due to other causes (for example, surgery) should be prescribed vigabatrin with caution. Children who are already registered blind, however, will have an altered risk:benefit ratio, possibly in favour of the drug. If the defect is identified the continued use of vigabatrin will depend on the overall clinical situation.

- Children taking vigabatrin whose seizures are well controlled should not automatically have the drug withdrawn. Current evidence suggests that the defect is unlikely to develop if perimetry gives normal results after more than three years of treatment.

- Vigabatrin remains the drug of choice for infantile spasms. Limited data suggest that it could be withdrawn without a relapse in infants who have been spasm free for six months.

- Other therapeutic indications include the treatment of children with partial epilepsy with or without secondary generalisation when other drug combinations have been ineffective or poorly tolerated. Vigabatrin seems to be particularly effective in children with seizures caused by tuberous sclerosis.

- Vigabatrin exacerbates typical absence and myoclonic seizures and should therefore not be prescribed in the idiopathic generalised epilepsies.

Vigabatrin Paediatric Advisory Group

Members of the group are: Richard Appleton, consultant paediatric neurologist, Liverpool (to whom correspondence should be addressed at the Roald Dahl EEG Unit, Alder Hey Children's Hospital, Liverpool L12 2AP); Peter Baxter, consultant paediatric neurologist, Sheffield; David Calver, consultant ophthalmologist, London; Celia Cramp, consultant paediatrician, Shrewsbury; John Gibbs, consultant paediatrician, Chester; Graham Harding, consultant clinical neurophysiologist, Birmingham; John Livingston, consultant paediatric neurologist, Leeds; Richard Robinson, consultant paediatric neurologist, London; Isabelle Russell-Eggitt, consultant paediatric ophthalmologist, London; Sheila Wallace, consultant paediatric neurologist, Cardiff; and John Wild, senior lecturer in vision sciences, Birmingham.

Competing interest: The group is supported by an educational grant from Hoechst Marion Roussel.

1 Appleton RE. Guideline may help in prescribing vigabatrin. BMJ 1998;317:1322.

2 Eke T, Talbot JF, Lawden MC. Severe, persistent visual field defect constriction associated with vigabatrin. BMJ 1997;314:180-1.

3 Wild JM, Martinez C, Reinshagen G, Harding GFA. Characteristics of a unique visual field defect attributed to vigaacteristics of a unique visual field

4 Harding GFA, Robertson K, Holliday I, Jones I Harding GFA, Robertson K, Holliday I, Jones L.
Field-specific visual-evoked potentials for assessment of Field-specific visual-evoked potentials for assessment of
peripheral field defect in a paediatric population.J Physiol

5 Krauss GL, Johnson MA, Miller NR. Vigabatrin-associated retinal cone dysfunction. Neurology 1998;50:614-8.

\section{Association between SSRIs and upper gastrointestinal bleeding}

\section{Coprescription of antiulcer drugs with SSRIs is fairly common}

EDITOR-The paper by de Abajo et al raises the possibility of an increased risk of upper gastrointestinal bleeding associated with
Risk for coprescription of antiulcer drugs with antidepressants as classified by Abajo et al ${ }^{1}$

\begin{tabular}{lccc} 
Drug & No of patients & $\begin{array}{c}\text { No of patients coprescribed } \\
\text { antiulcer drugs }\end{array}$ & Odds ratio (95\% $\mathbf{~ C l )}$ \\
\hline \begin{tabular}{l} 
Selective serotonin reuptake inhibitor \\
\hline $\begin{array}{l}\text { Non-selective serotonin reuptake } \\
\text { inhibitor (mainly tricyclic } \\
\text { antidepressants) }\end{array}$
\end{tabular} & 4288 & 585 & $1.6(1.4 \text { to } 1.7)^{*}$ \\
\hline $\begin{array}{l}\text { Other antidepressant without } \\
\text { serotoninergic effects }\end{array}$ & 5225 & 480 & $1.7(1.6 \text { to } 1.9)^{*}$ \\
\hline
\end{tabular}

${ }^{*} \mathrm{P}<0.05$

selective serotonin reuptake inhibitors. ${ }^{1}$ The authors excluded patients with cancer, oesophageal varices, Mallory-Weiss disease, alcoholism, liver disease, and coagulopathies, but it is not clear if they excluded patients who were coprescribed antiulcer treatments. They do mention antecedents of upper gastrointestinal disorders as potential cofounders that were adjusted for.

To investigate this issue further we examined a large prescription database provided by the general medical services in the Republic of Ireland. For November 1998 we determined the odds ratios to estimate the relative risk for the coprescription of antiulcer drugs (including $\mathrm{H}_{2}$ antagonists, proton pump inhibitors, and prostaglandin analogues but excluding antacids) with selective serotonin reuptake inhibitors and other antidepressants (table). We excluded people who were coprescribed aspirin, nonsteroidal anti-inflammatory agents, or corticosteroids as this may have been cytoprotective coprescribing. This left a total of 95929 patients for analysis, of whom 8921 received prescriptions for antiulcer drugs. There was a significant correlation between the prescribing of antidepressants of all types and antiulcer drugs.

In the past, tricyclic antidepressants were used to treat peptic ulcer disease because of their antimuscarinic effects, but because of poor efficacy they are now not used for this. The newer selective serotonin reuptake inhibitors may have fewer antimuscarinic side effects, although they have gastrointestinal side effects such as vomiting, dyspepsia, and abdominal pain. Paradoxically, antidepressants (in particular, selective serotonin reuptake inhibitors) have been recommended in functional dyspepsia. ${ }^{2}$

Coprescribing of antiulcer drugs with antidepressants may indicate patients with depression who have dyspeptic symptoms, an increased prevalence of peptic ulcer disease in patients with depression, or an increased prevalence of depression in patients with peptic ulcer disease. Whatever the true association between these conditions, an increased risk of bleeding from peptic ulcer disease would be expected on the basis of these data.

D Williams lecturer in clinical pharmacology and therapeutics williamd@tcd.ie

A Kelly senior lecturer in biostatistics

J Feely professor of pharmacology and therapeutics Departments of Pharmacology and Therapeutics and Community Health and General Practice, Trinity Centre for Health Sciences, St James Hospital, Dublin 8, Republic of Ireland

Competing interests: None declared.
1 De Abajo FJ, Garcia Rodríguez LA, Montero D. Association between selective serotonin reuptake inhibitors and upper gastrointestinal bleeding: population based case-control study. BMJ 1999;319:1106-9. (23 October.)

2 Talley NJ, Axon A, Bytzer P, Holtmann G, Lam SK, Zanten SV. Management of uninvestigated and functional dyspepsia: a working party report for the World Congresses of Gastroenterology 1998. Aliment Pharmacol Ther 1998;13:1135-48

\section{SSRIs are no more likely than other} drugs to cause such bleeding selective serotonin reuptake inhibitors increase the risk of upper gastrointestinal bleeding, possibly by an effect on the haemostatic function of platelets. ${ }^{1}$ This conclusion, however, is based on a case-control study that included only cases that required referral or admission to hospital and excluded cases of Mallory-Weiss syndrome or oesophageal bleeding. It is not clear how controls were selected: they might have included patients with an upper gastrointestinal bleed but who had not been admitted to hospital.

Using prescription event monitoring, we have carried out observational studies on large cohorts of patients taking selective serotonin reuptake inhibitors, other antidepressants, and many other drugs. ${ }^{2}$ This technique uses exposure data from the Prescription Pricing Authority for general practitioners' prescriptions in England and outcome data on events, recorded on forms completed by the prescribing doctor. In our database we have data on 74 drugs, of different therapeutic classes.

We have reviewed our data on events coded as gastrointestinal bleeding during exposure to selective serotonin reuptake inhibitors and two of the other drugs on our database. These two were chosen to show the baseline rate of gastrointestinal bleeding in the population presenting to a general practitioner, where there is probably no confounding by indication or concurrent illnesses and drugs.

The table gives the results, which show a non-significant difference in rate between the two groups. This also applied when the patients were stratified by age (1-59 and $\geqslant 60$ years): rate ratios (95\% confidence intervals) were 1.27 (0.83 to 1.96$)$ and 1.34 (0.83 to 2.18) respectively. If "haemorrhage gastrointestinal upper" was taken as the only outcome event the rate ratio was $1.30(0.75$ to 2.27); again, stratification by age made no significant difference. We also compared selective serotonin reuptake inhibitors with venlafaxine (an antidepressant with mixed serotoninergic and adrenergic effects); the
EDitor-De Abajo et al suggest that 
Rate of gastrointestinal bleeding during treatment with selective serotonin reuptake inhibitors (SSRIs) and assumed baseline rate with comparator drugs

\begin{tabular}{lcccc} 
Drugs taken & No of events* & $\begin{array}{c}\text { Patient months of } \\
\text { exposure }\end{array}$ & $\begin{array}{c}\text { Rate/1000 patient } \\
\text { months of treatment }\end{array}$ & Rate ratio (95\% Cl) \\
\hline SSRIs $†$ & 103 & 237609 & 0.43 & $1.24(0.91$ to 1.70) \\
\hline Comparator drugs $\ddagger$ & 72 & 205431 & 0.35 & 1 \\
\hline
\end{tabular}

${ }^{*}$ Coded as any of: haemorrhage gastrointestinal, haemorrhage gastrointestinal upper, haemorrhage rectal, haemorrhagic diarrhoea.

†Fluvoxamine, fluoxetine, paroxetine, sertraline, and nefazodone.

$\ddagger$ Moclobemide and salmeterol.

rates were not significantly different (rate ratio $0.75(0.50$ to 1.17$))$.

The advantage of these analyses is that all gastrointestinal bleeds recorded by the general practitioner are included, not simply those requiring hospital referral. Our results may therefore give a more valid picture of the situation in clinical practice than those in de Abajo et al's study. Thus we can find no evidence to suggest that selective serotonin reuptake inhibitors are more likely to cause gastrointestinal bleeding than other drugs.

N R Dunn senior research fellow

n.dunn@dsru.u-net.com

G L Pearce manager, data processing

S A W Shakir director

Drug Safety Research Unit, Southampton

SO31 1AA

Competing interests: The Drug Safety Research Unit receives charitable donations from pharmaceutical companies, but these companies have no operational or editorial control over the unit's work.

1 De Abajo FJ, Garcia Rodríguez LA, Montero D. Association between selective serotonin reuptake inhibitors and upper gastrointestinal bleeding: population based case-control study. BMJ 1999;3 19:1106-9. (23 October.)

2 Dunn N, Mann RD. Prescription-event and other forms of epidemiological monitoring of side-effects in the UK. Clin Experimental Allergy 1999;29(suppl 3):217-39.

\section{Self treatment with non-steroidal drugs may be confounding factor}

EDITOR-De Abajo et al concluded that selective serotonin reuptake inhibitors are associated with an increased risk of upper gastrointestinal bleeding, particularly when combined with non-steroidal antiinflammatory drugs. ${ }^{1}$ They seemed to show a convincing association between degree of selectivity and relative risk. We have concerns that important factors have been overlooked.

Although patients with alcoholism were excluded, heavy drinkers are generally poorly identified in general practice. The authors might therefore not have identified a number of gastrointestinal bleeds secondary to alcohol misuse. Furthermore, depression is associated with several painful conditions such as menstrual disorders, ${ }^{2}$ arthritis, ${ }^{3}$ and back pain. ${ }^{4}$ These conditions frequently lead to self treatment with over the counter analgesics, which is likely to include substantial use of non-steroidal antiinflammatory drugs.

General practitioners lack awareness of the prevalence of self treatment with non-steroidal drugs, ${ }^{5}$ and de Abajo et al consider their prescription data to be complete. But the United Kingdom general practice research database would be unable to identify the use of over the counter non-steroidal drugs in a substantial group of patients-specifically those with depression associated with pain. Therefore undue bias may be placed on the role of the antidepressant in the aetiology of gastrointestinal bleeding. Prospective studies that take such confounding variables into account are required before a causal relation between selective serotonin reuptake inhibitors and gastrointestinal bleeding can be shown.

Tim Dickinson specialist registrar in general adult psychiatry

Saj Malhi senior house officer in psychiatry

Susan Painter senior house officer in psychiatry

Jonathon Pyott senior house officer in psychiatry

Avleen Sawhney senior house officer in psychiatry

Aylesbury Vale Healthcare NHS Trust, Aylesbury,

Buckinghamshire HP20 1EG

Competing interests: None declared.

1 De Abajo FJ, Garcia Rodríguez LA, Montero D. De Abajo FJ, Garcia Rodríguez LA, Montero D
Association between selective serotonin reuptake inhibiAssociation between selective serotonin reuptake inhibicase-control study. BMJ 1999;3 19:1 106-9. (23 October.) case-control study. BMJ 1999;319:1 106-9. (23 October.)
2 Bancroft J, Rennie D, Warner P. Vulnerability to

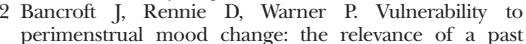
perimenstrual mood change: the relevance of a past
history of a depressive disorder. Psychosom Med history of a depressive disorder. Psychosom Med
1994;56:225-31.

3 Abdel-Nasser AM, Abd El-Azim S, Taal E, El-Badawy SA, Rasker JJ, Valkenburg HA. Depression and depressive symptoms in rheumatoid arthritis patients: an analysis of
their occurrence and determinants. $\mathrm{Br} J$ Rheumatol 1998:37:391-7.

4 Waxman R, Tennant A, Helliwell P. Community survey of factors associated with consultation for low back pain. BMJ 1998;317:1564-7.

5 Pal B. GPs lack awareness of non-steroidal antiinflammatory drugs available over the counter. $B M J$ 1996;313:116.

\section{Authors' reply}

EDITOR-Williams et al postulate that the increased risk of upper gastrointestinal bleeding found in association with the use of selective serotonin reuptake inhibitors might be confounded by an association of depression with peptic ulcer disease. We think that this potential association cannot explain our results for three main reasons.

Firstly, we controlled for antecedents of upper gastrointestinal disorders, including dyspepsia. Furthermore, if we restrict our analysis to patients without any upper gastrointestinal antecedent the results are essentially the same (relative risk of upper gastrointestinal bleeding for selective serotonin reuptake inhibitors 3.3 (95\% confidence interval 2.0 to 5.5); for the nonselective group 1.8 (1.2 to 2.6$)$ ).

Secondly, the increased risk was not observed to the same extent with all classes of antidepressants but mainly with selective serotonin reuptake inhibitors.

Thirdly, if depression were secondary to peptic ulcer the risk of bleeding would revert to the baseline value after the first few months of treatment, but this was not the case, as we stated in the paper.

We have reanalysed our data and included the use of antiulcer drugs (antacids, omeprazole, and $\mathrm{H}_{2}$ blockers) in the model: the results hardly change (relative risk of upper gastrointestinal bleeding for selective serotonin reuptake inhibitors 2.9 (2.0 to 4.2); for the non-selective group 1.3 (1.0 to 1.8)).

Dunn et al suggest that our results may not be valid because we included as controls patients with minor upper gastrointestinal haemorrhage. We did this because our source of information was a general practice database, not a hospital based database. We identified potential cases through general practitioners' computerised records, which obviously included cases of minor gastrointestinal bleeding. But to enhance the validity of case ascertainment we selected as cases only those with the more serious outcomes. All potential cases (including cases of minor bleeding) not selected were consequently not eligible to serve as controls. Dunn et al do not present any convincing reason why readers should consider their approach to be more valid than ours.

Finally, Dickinson et al raise the interesting hypothesis that use of over the counter non-steroidal anti-inflammatory drugs could partially account for the increased risk associated with selective serotonin reuptake inhibitors, because pain is a common feature of depressive episodes. Unfortunately, we cannot test such a hypothesis, but the lack of a homogeneous pattern with all antidepressants speaks against that bias. Our study was intended to test a hypothesis raised by spontaneous reports and supported by biological evidence. The results obtained are consistent with this hypothesis, but we are aware that further studies are necessary.

Francisco J de Abajo head

Dolores Montero head, safety evaluation unit, División de Farmacoepidemiología y Farmacovigilancia Agencia Española del Medicamento, Madrid, Spain

Luis Alberto García Rodríguez director Centro Español de Investigación Farmacoepidemiológica, Madrid, Spain

Competing interests: For the past five years Dr Rodríguez has received research grants from Novartis, which manufactures several antidepressants.

\section{Heartburn treatment in primary care}

Prescribing omeprazole would conflict with desire to control prescribing costs EDITOR-Hatlebakk et al suggest that omeprazole $20 \mathrm{mg}$ once daily should be considered as a first choice when patients with heartburn are being treated in primary care. ${ }^{1}$ With the formation of primary care groups all general practitioners are coming under increasing pressure to control prescribing costs. If costs are exceeded in one budget, budgets in other clinical areas (such as staff, including practice nurses) may be threatened. I and my colleagues in the practice have worked hard over two years to con- 
trol our prescribing costs. Omeprazole was the largest single gastrointestinal drug cost, accounting for $7 \%$ of our total drug budget and just over half of our gastrointestinal drug costs.

Hatlebakk et al make no mention of lifestyle advice-such as advice on smoking, diet, and weight reduction-as a method of controlling symptoms. Recent recommendations from our primary care group (through the primary care investment plan) suggest that we should target the use of proton pump inhibitors, and this will be linked to an element of payment that we receive under the prescribing incentive scheme. Increasingly we are using histamine receptor antagonists both as first line treatment of symptomatic reflux and as intermittent maintenance treatment. We are going to find considerable conflict in following Hatlebakk et al's recommendations.

Alexander Williams general practitioner St Thomas Health Centre, Exeter EX4 1H] su1838@eclipse.co.uk

Competing interests: Dr Williams's practice receives a research and development grant from South and West Regional Health Authority.

1 Hatlebakk JG, Hyggen A, Madsen PH, Walle PO, Schulz T, Mowinckel $\mathrm{P}$, et al. Heartburn treatment in primary care: randomised double blind study for 8 weeks. $B M$ J 1999;319:550-3. (28 August.)

\section{Step up approach to management is best}

EDITOR-Hatlebakk et al's study supports the empirical treatment of heartburn in a primary care setting. ${ }^{1}$ But the authors' conclusion that "omeprazole should be considered as a first choice when treating patients with heartburn in primary care" is unsupported by their findings that a proton pump inhibitor is more effective than cisapride in the empirical treatment of heartburn.

Because of the enormous cost of proton pump inhibitors to the NHS we favour the step up approach to managing patients with heartburn in primary care. Advice on lifestyle and use of antacids should be given initially, and $\mathrm{H}_{2}$ antagonists and proton pump inhibitors should be given only for patients with unresolved symptoms. ${ }^{2}$

Sonia Saxena research fellow

Department of General Practice, St George's Hospital Medical School, London SW17 0RE saxena@sghms.ac.uk

Richard C G Pollok research fellow

Digestive Diseases Research Centre, St

Bartholomew's and The Royal London School of

Medicine and Dentistry, London E1 2AT

Funding: SS South Thames Research and Development Fund, RP WellcomeTrust

Competing interests: None declared.

1 Hatlebakk JG, Hyggen A, Madsen PH, Walle PO, Schulz T, Mowinckel P, et al. Heartburn treatment in primary care: randomised double blind study for 8 weeks. $B M J$ 1999;319:550-3. (28 August.)

2 Eggleston A, Wigerinck A, Huijghebaert S, Dubois D, Hay$\operatorname{cox}$ A. Cost effectiveness of treatment for gastro-intestinal reflux disease in clinical practice: a clinical database analysis. Gut 1998;42:13-6.

\section{Study's results seem to be promotional} rather than evidence based

EDiton-Hatlebakk et al's study on heartburn in primary care shows clearly many of the problems of research sponsored by pharmaceutical companies.

Firstly, health professionals in primary care are not asking the question being studied. We already know that omeprazole is more effective than cisapride, from evidence $^{2}$ and experience, and do not need a further expensive, multicentre trial by the makers of omeprazole to prove it.

Secondly, the authors' conclusion that "omeprazole should be considered as a first choice when treating patients with heartburn in primary care" seems to be promotional rather than a balance of all the available evidence. Even if this study had found omeprazole to be more effective than antacids, all $\mathrm{H}_{2}$ antagonists, and all other proton pump inhibitors, recommended treatment of simple heartburn would probably still be to follow a step approach as recommended by the National Prescribing Centre. The authors' conclusion is not evidence based and puts across the wrong message at this important time for primary care.

Thirdly, the real agenda in primary care lies elsewhere. Our real dilemma in primary care is how to reduce prescribing of proton pump inhibitors rather than increase it. In Teesside, as I'm sure in other regions, omeprazole is already on the top of the prescribing bill and we are trying to use lower doses of the drug or to use treatment on an intermittent basis. ${ }^{4}$

If the huge amount of money used to fund studies such as this was instead used to reduce the cost of omeprazole it would be many times more beneficial to the NHS, primary care, and our patients.

Hugh Alberti general practitioner

502-8 Normanby Road, Middlesbrough TS6 9BZ hugh@lone.demon.co.uk

Competing interests: None declared.

1 Hatlebakk JG, Hyggen A, Madsen PH, Walle PO, Schulz T, Mowinckel P, et al. Heartburn treatment in primary care: Mowinckel P, et al. Heartburn treatment in primary care:
randomised, double blind study for 8 weeks. $B M J$ randomised, double blind

Galmiche J-P, Barthelemy P, Hamelin B. Treating the 2 Galmiche J-P, Barthelemy P, Hamelin B. Treating the symptoms of gastro-oesophageal reflux disease: a doubleblind comparison of omepraz

Pharmacol Ther 1997;11:765-73

3 National Prescribing Centre. Proton pump inhibitors: thei role in dyspepsia. MEREC Bull 1998;9:41-

4 Bardhan KD, Müller-Lissner S, Bigard MA, Porro GB, Ponce J, Hosie J, et al. Symptomatic gastro-oesophagea reflux disease: double blind controlled study of intermittent treatment with omeprazole or ranitidine. $B M$ 1999;318:502-7.

\section{Authors' reply}

EDIToR-Williams, Saxena, and Alberti raise a relevant issue for all patients. The cost to patients and society is particularly important for a chronic disease such as gastrooesophageal reflux disease. Cost effectiveness in terms of adequate symptom relief and avoiding expensive and scarce specialist care should also be considered.

Our study was designed and performed by primary care physicians and gastroenterologists working closely in networks. Gastrooesophageal reflux disease is common in primary care and can usually be treated there. Prokinetic treatment with cisapride has been advocated as an alternative to acid suppression. Budget restrictions and time limits did not allow us to assess an $\mathrm{H}_{2}$ receptor antagonist.

In Norway the recommended dose of cisapride $20 \mathrm{mg}$ twice daily costs NOK 19.10 per day and that of omeprazole $20 \mathrm{mg}$ every morning NOK 18.90 per day (NOK $1=80 \mathrm{p})$. Ranitidine $150 \mathrm{mg}$ twice daily costs NOK 10.30 and $300 \mathrm{mg}$ twice daily NOK 18.80 per day. Marginal differences in cost highlight the fundamental question of effectiveness and cost effectiveness of each drug regimen. Other studies, including studies in primary care, have shown proton pump inhibitors to be superior to $\mathrm{H}_{2}$ receptor antagonists. ${ }^{1}$ Prices for proton pump inhibitors are likely to decrease in the near future.

We were astonished by the severity of heartburn and other symptoms in our patients. Heartburn occurred on average 5.5 days per week and affected daily activities in $65 \%$ of patients. Symptom relapse occurred in $72 \%$ within six months. Few of these patients, however, had severe disease requiring specialist care. The focus should therefore be on adequate relief of symptoms in primary care.

Lifestyle advice was recommended, but, in our experience, lifestyle modifications are difficult to maintain. Patients with reflux symptoms have usually adjusted their diet and used antacids with only limited relief.

We have repeatedly observed undertreatment of gastro-oesophageal reflux disease in primary care. Doctors must listen to patients and understand the need for symptom control and how reflux symptoms affect overall health. Treatment should be individualised, allowing for intermittent and long term use of $\mathrm{H}_{2}$ receptor antagonists and proton pump inhibitors. We agree that a step up approach, starting with an $\mathrm{H}_{2}$ receptor antagonist, is often reasonable, although a significant effect of $\mathrm{H}_{2}$ receptor antagonists in long term treatment has been difficult to show. Our study shows that cisapride has no place in the treatment of heartburn in primary care.

Rapid relief of symptoms is important in this disease because treatment is usually used as an uncontrolled diagnostic test. Inadequate treatment will inevitably lead to higher referral rates for endoscopic examination.

Proton pump inhibitors must be used correctly, especially in patients with gastrooesophageal reflux disease. A step up approach is often correct, but more effective acid suppression may be needed in a large proportion of patients.

\section{J G Hatlebakk assistant professor}

jan.hatlebakk@haukeland.no

A Berstad professor

Department of Medicine, Haukeland Sykehus, University of Bergen, N-5021 Bergen, Norway

P H Madsen specialist in primary care medicine N-5148 Bergen, Norway

$\mathbf{P} \mathbf{O}$ Walle specialist in primary care medicine N-4900 Tvedestrand, Norway

Competing interests: Professors Hatlebakk and Berstad have accepted fees from Astra Norge and Janssen Cilag for speaking.

1 Hungin APS, Gunn SD, Bate CM, Turbitt ML, Wilcock C, Richardson PDI. A comparison of the efficacy of omeprazole $20 \mathrm{mg}$ once daily with ranitidine $150 \mathrm{mg}$ bd in the relief of symptomatic gin the relief of symptomatic gastro-oesophageal reflux disease in
general practice. Br J Clin Res 1993;4:73-88. 


\section{Incidence of congenital rubella in Greece has decreased}

EDITOR-In their paper on the increase in congenital rubella occurring after immunisation in Greece, Panagiotopoulos et al used information that covered the period only until $1995 .{ }^{1}$ Since then the surveillance of rubella and immunisation policies have changed. In 1998 the National Center for Surveillance and Intervention was established and a new computerised surveillance system was introduced.

In September 1998 an outbreak of rubella was detected in army camps; it peaked in January 1999. Altogether 1174 cases were reported among unvaccinated male recruits aged 18-22 years. In January 1999 the outbreak spread to the community and an additional 1306 cases were reported. Related cases in other European countries were also reported. ${ }^{2}$ The average age of cases was 17.12 (SD 5.5) years; $96 \%$ of cases occurred among people who had not been vaccinated, and $60 \%$ of cases occurred among men. Four confirmed cases of congenital rubella syndrome were reported after the outbreak.

Although there continue to be outbreaks, the total number of cases has decreased and the interval between the outbreaks has gradually increased (figure). Our data do not show a real increase in the incidence of congenital rubella. We believe that Panagiotopoulos et al's data do not confirm an increase because data from an active, retrospective surveillance system in 1993-4 were compared with poor quality preexisting data from passive surveillance.

The ongoing outbreaks and subsequent cases of congenital rubella can be only partially explained by comparatively low vaccine coverage and inconsistencies in immunisation policies. The existence of high risk unvaccinated groups that can trigger a community outbreak is important. The outbreaks which occur in the community in Greece every 3-6 years correspond to outbreaks in the army (figure). Analysis of the data indicated that the recent outbreak in the military preceded the one in the com-

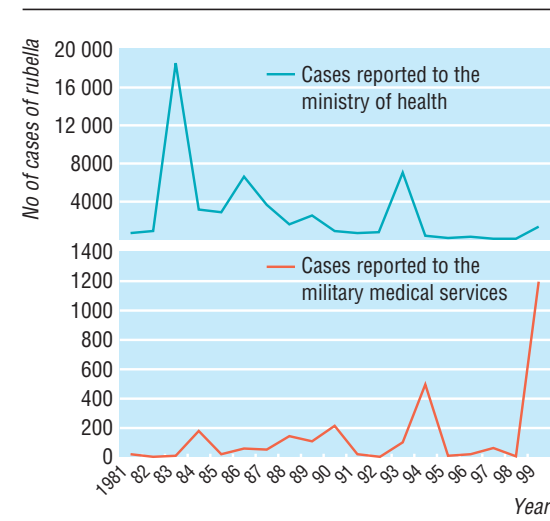

Distribution of cases of rubella reported to the health ministry and the military medical services in Greece, 1982-99 munity. Spatial analysis of the geographical distribution of cases showed that community outbreaks started in districts of the country where army camps were located. ${ }^{3}$ Crowding and other stressful conditions among unvaccinated recruits within military camps can alter the effectiveness of the herd immunity there, which is different from that in the community. ${ }^{4}$

In April 1999 the Greek advisory committee for immunisations lowered the age for children receiving the second dose of MMR (measles-mumps-rubella) vaccine from 11-12 years to 4-6 years and recommended vaccinating all children and young adults younger than 18 years who had not yet been vaccinated. ${ }^{5}$ Vaccinating all recruits who have not been vaccinated is also being considered.

We believe that these measures will prevent future outbreaks and eliminate subsequent cases of congenital rubella syndrome.

G Giannakos director, communicable diseases clinic Hellenic Army Medical Corps Directorate, Katchaki and Mesogeion 138, 11525 Athens, Greece

M Pirounaki infection specialist

C Hadjichristodoulou director

National Center of Surveillance and Intervention,

Makedonias 6-8 Str, 10433 Athens, Greece

hadjich@ath.forthnet.gr

1 Panagiotopoulos T, Antoniadou I, Valassi-Adam E. Increase in congenital rubella occurrence after immunisation in Greece: retrospective survey and systematic review $B M J$ 1999:319:1462-6. (4 December)

2 Rubella in university students. Commun Dis Rep CDR Wkb $1999 \cdot 9 \cdot 113-6$

3 Hadjichistodoulou Ch, Papatheodorou F Soteriades G, Padjichristodoulou Ch, Papatheodorou E, Soteriades G, Pancioniog cal study of brucellosis in eight Greek villages using computerized mapping programme. Eur J Epidemiol

4 Perez-Trallero E, Cilla G, Urbieta M. Rubella immunization of men: advantages of herd immunity. Lance 1996;348:413.

5 Centers for Disease Control and Prevention. Measles, mumps, and rubella. MMWR Morb Mortal Wkly Rep 1998;47(RR-8):1-57.

\section{Points for reading as part of continuing medical education}

\section{e-Journal club allows doctors to gain points}

EDITOR-Holm raises several issues in his editorial which asks whether doctors should earn continuing medical education points for reading. ${ }^{1}$ Here in the north of Scotland a scheme is under development to recognise the journal reading done by general practitioners in their own time. The Highland e-Journal Club will offer the opportunity for general practitioners to post references to articles that they have found particularly interesting or relevant together with an explanation of why. These will be posted on a bulletin board hosted on our website (www.inverness-pgmc.demon co.uk/), which will be fully searchable. It will also be possible to post comments on previous contributions. Five contributions will count as half a session for the post graduate education allowance and continuing medical education credits (13/4 hours).

This simple idea addresses many of the issues raised by Holm-namely, it
- Recognises reading as a legitimate activity for continuing professional development - Provides a written statement of reading, which may be used in a portfolio

- Is truly self directed rather than being concerned with "specially designated articles," and

- Encourages reflection as a core part of the educational process.

Additionally, it

- Is a format similar to a traditional journal club but without the time commitment

- Produces a valuable study resource for others, and

- Allows views to be shared and ideas to be exchanged and developed.

Miles Mack associate adviser for continuing professional development

North of Scotland Institute of Postgraduate Medical Education, Raigmore Hospital, Inverness IV2 3UJ drmbm@hotmail.com

1 Holm HA. Should doctors get CME points for reading? BMJ 2000;320:394-5. (12 February.)

\section{How about earning points for continuing} medical entertainment?

EDITOR-Reading is not the only alternative source of continuing medical education that should be considered. ${ }^{1}$ Without BBC radio's long running series The Archers I might never have qualified as a doctor. I passed my final medical examinations thanks to my memory of a character's illness and treatment. I owe my knowledge of polymyalgia rheumatica to a radio soap opera.

A recent storyline about depression illustrated how medical drama can have an educational role. This "case study" was a powerful reminder that an individual's illness can affect a whole family. The audience was able to understand the complex aetiology of depression, could follow the slow and rocky recovery, and, many weeks later, were reminded of the repercussions of depression. In a similar way to the depiction of schizophrenia in the television soap Eastenders, this portrayal of depression may have dispelled some of the stigma of mental illness. ${ }^{2}$

My radio education has not stood still. Thanks to The Archers I have recently learnt about the role of the "terminator gene" in genetic modification, learnt the details of cataract removal, and been reminded of the dangers of congenital heart disease. How many points is that worth in my Continuing Medical Entertainment?

Jim Bolton lecturer in psychiatry

St George's Hospital Medical School, London SW17 0RE

jgbolton@sghms.ac.uk

1 Holm HA. Should doctors get CME points for reading? BMJ 2000;320:394-5. (12 February.)

2 Revely A. Soap tackles stigma of schizophrenia. BMJ 1997;314:1560.

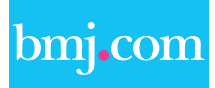

Rapid responses

Correspondence submitted electronically is available on our website 